\title{
Médiévales
}

Langues, Textes, Histoire

70 | printemps 2016

Lieux d'hygiène et lieux d'aisance en terre d'Islam (VII ${ }_{-}$ $\mathrm{XV}^{\mathrm{e}}$ siècle)

\section{Robert JACOB, La Grâce des juges. L'institution judiciaire et le sacré en Occident}

Paris, PUF, 2014, 515 p.

Isabelle Mathieu

\section{OpenEdition}

\section{Journals}

Édition électronique

URL : http://journals.openedition.org/medievales/7761

DOI : 10.4000/medievales.7761

ISSN : $1777-5892$

Éditeur

Presses universitaires de Vincennes

Édition imprimée

Date de publication : 23 juin 2016

Pagination : 281-282

ISSN : 0751-2708

\section{Référence électronique}

Isabelle Mathieu, «Robert JAСOB, La Grâce des juges. L'institution judiciaire et le sacré en Occident », Médiévales [En ligne], 70 I printemps 2016, mis en ligne le 20 juillet 2016, consulté le 24 septembre 2020. URL : http://journals.openedition.org/medievales/7761 ; DOI : https://doi.org/10.4000/ medievales.7761

Ce document a été généré automatiquement le 24 septembre 2020.

Tous droits réservés 


\section{Robert JACOB, La Grâce des juges. L'institution judiciaire et le sacré en Occident}

Paris, PUF, 2014, 515 p.

Isabelle Mathieu

\section{RÉFÉRENCE}

Robert JACOB, La Grâce des juges. L'institution judiciaire et le sacré en Occident, Paris, PUF, 2014,515 p.

1 Juriste et médiéviste, Robert Jacob livre dans son ouvrage intitulé La Grâce des juges. L'institution judiciaire et le sacré en Occident une réflexion fouillée et personnelle sur «l'interaction de la procédure et du sacré »(p.11), avec en toile de fond une place centrale accordée à l'ordalie qui marque «le point de départ de cette recherche » (p. 17). Ce texte de 503 pages se décline en neuf temps : « Les ordalies : anthropologie et histoire »; " La promesse du jugement de Dieu »; " Des royaumes de justice »; "L'acte de juger dans l'histoire des mots»; «Le serment des juges ou l'invention de la conscience judiciaire "; "Le pape, l'enquête et la vérité»; «La formation de la déontologie judiciaire »; "Juger sous le ciel. Allers et retours d'Occident en Chine » et «La grâce des juges ». Ces neuf chapitres sont ensuite à leur tour divisés en souschapitres (entre quatre et onze selon les parties), ce qui rend facile à suivre le fil conducteur de la pensée de l'auteur. Si ce dernier a fait le choix d'un plan thématique, il n'en oublie pas pour autant de mettre en avant la dynamique chronologique et de mobiliser une aire géographique très large dépassant le cadre strict de l'Occident (Asie, Afrique...). À cet égard, par exemple, Robert Jacob rappelle combien les XII ${ }^{\mathrm{e}}$ et XIII siècles ont constitué " un grand moment de rationalisation juridique » de laquelle a découlé la disparition des ordalies (p.191). Il souligne d'ailleurs une différence importante entre les royaumes de France et d'Angleterre, à savoir qu' « à la fin du $\mathrm{XI}^{\mathrm{e}}$ et 
plus encore au XII , la pratique de l'ordalie a atteint en Angleterre une intensité que n'a connue aucune autre société médiévale, avant de disparaître brusquement au début du siècle suivant ", ce qui n'a pas été le cas en France (p. 180). Dès que les choses s'y prêtent, il inscrit également ses travaux dans le temps long, montrant comment, par exemple, le Parlement de Paris a su au fil des siècles se poser "en garant de la discipline de tous les juges du royaume » (p. 324), ou en faisant des parallèles avec le domaine judiciaire tel qu'il se donne à voir de nos jours, ce qui l'amène à rappeler par exemple qu'«au Moyen Âge comme aujourd'hui, une écrasante majorité de procès civils se concluent par une transaction et qu'il en va de même au pénal, où à toute époque et sous diverses formes, le «plaider coupable » l'emporte de beaucoup dans les statistiques judiciaires sur la marche au verdict» (p. 455); ces considérations sont, me semble-t-il, importantes, puisqu'elles permettent au passage de revenir sur un certain nombre de clichés encore trop souvent véhiculés au sujet de l'organisation et le fonctionnement de la justice médiévale.

D'un point de vue méthodologique, Robert Jacob accorde une large place à la comparaison, ce qui le conduit à dresser le constat que «l'originalité de l'Occident a bien tenu aux modes de communication qui s'y sont mis en place entre la justice relative des hommes et la justice divine absolue » (p. 409), tout comme il revisite tout au long de son ouvrage l'historiographie en lien avec son objet d'étude. Ainsi, concernant les ordalies qui sont au centre de son propos, il remarque que le fait "qu'elles aient été si anciennes, et partout si répandues dans des formes similaires, devrait dissuader définitivement de leur chercher des origines ethniques particulières, celtiques, germaniques ou autres, comme on l'a trop souvent fait» (p. 131). Comme l'auteur le dit lui-même, «sans jamais lâcher le fil conducteur de l'histoire médiévale, le présent livre multiplie les incursions dans des champs disciplinaires différents, de l'africanisme à la sinologie en passant par l'histoire littéraire, le droit canonique, la common law, etc. » (p. 511), ce qui justifie en partie qu'il n'a pas fait le choix de proposer une "classique " bibliographie récapitulative - qui aurait été à coup sûr très dense et difficile à mettre en œuvre - mais plutôt de suggérer un certain nombre de lectures au fur et à mesure des notes de bas de pages. Ces dernières permettent ainsi d'approfondir judicieusement des points précis, notamment tout ce qui concerne la Chine dont l'histoire nous est moins familière.

3 Sur la forme comme sur le fond, l'ouvrage fait preuve d'une grande rigueur et ne laissera pas indifférent le lecteur qui s'intéresse au domaine judiciaire; les idées soulevées invitent naturellement à la réflexion. Bien construit, l'ouvrage est clair et sa lecture très agréable. On notera par ailleurs la place faite à la sémantique: régulièrement, Robert Jacob se pose la question de savoir quel mot est utilisé pour désigner le sacré et le judiciaire et quelle est l'origine de ces vocables employés, ce qu'il fait par exemple très naturellement avec le terme d'ordalie (p. 30). S'il propose une démarche qui par bien des aspects est très conceptuelle, il n'en oublie pas pour autant d'ancrer ses propos dans le réel en mobilisant des exemples précis. Ces derniers, insérés au fil de la plume ou isolés sous forme de petits paragraphes, permettent de saisir par exemple toute la richesse des normes juridiques, des sources scripturaires et de la pratique judiciaire. L'auteur rappelle d'ailleurs que "les archives judiciaires de la France médiévale et moderne se prêtent fort bien à l'histoire sociale car elles fourmillent de données, souvent d'ailleurs surabondantes au regard de l'objet des procès» (p. 462). Enfin, à travers cet ouvrage, Robert Jacob donne aux lecteurs 
l'occasion d'observer ces juges au travail et l'univers dans lequel ils gravitent; un environnement fait de questionnements et d'incertitudes.

Il montre ainsi avec talent de quelle façon se sont forgées les qualités propres au juge (impartialité, devoir de diligence, amour de la justice et de la vérité) (p. 315-316) et rappelle par exemple que certaines ordonnances des rois de France ont posé dès le Moyen Âge des principes propres à la discipline judiciaire, ce qui a permis d'ébaucher une sorte d'archétype de la déontologie du juge (p. 317) dont le serment constitue l'acte fondateur de la fonction de juger. Cependant, Robert Jacob souligne également que « la source vivante de la responsabilité du magistrat était moins le texte législatif, dont le catalogue des devoirs et des interdits n'avait rien d'exhaustif, que l'engagement solennel par lequel il s'était lié devant Dieu » (p. 321). En effet, à plusieurs reprises, l'auteur revient sur le rapport au divin, un aspect qui est très important à prendre en compte pour comprendre le domaine judiciaire à cette époque. Ayant le souci d'ancrer ses propos dans le réel, Robert Jacob se pose également la question de l'intégrité de ces hommes de justice dans leur pratique quotidienne de la justice. Reprenant un certain nombre de travaux portant sur le sujet, il souligne que, de manière générale, «la corruption n'a jamais constitué un mal endémique de la justice occidentale » (p. 326) et, plus précisément si l'on s'appuie, par exemple, sur les archives du Parlement de Paris, qu'« à la fin du Moyen Âge, les actions contre les juges représentaient, selon les années, de 2 à $5 \%$ du total des affaires ", ce qui est somme toute assez peu (p. 325).

Pour achever son ouvrage, l'auteur délaisse la traditionnelle conclusion pour proposer quelques pages qu'il intitule " Perspective ", ce qui suggère que cette recherche est loin d'avoir livré tous ses résultats. La Grâce des juges. L'institution judiciaire et le sacré en Occident est un ouvrage passionnant, bien organisé et riche sur le sujet; on ne peut qu'en recommander la lecture. 